\title{
Phosphatidic Acid as a Second Messenger in Human Polymorphonuclear Leukocytes

\author{
Effects on Activation of NADPH Oxidase
}

David E. Agwu," Linda C. McPhail,"* Silvano Sozzani," David A. Bass, ${ }^{\star}$ and Charles E. McCall*

${ }^{*}$ Section on Infectious Diseases, ${ }^{\ddagger}$ Pulmonary/Critical Care, Department of Medicine, and ${ }^{\S}$ Department of Biochemistry,

Wake Forest University Medical Center, Winston-Salem, North Carolina 27103

\begin{abstract}
Receptor-mediated agonists, such as FMLP, induce an early, phospholipase D (PLD)-mediated accumulation of phosphatidic acid (PA) which may play a role in the activation of NADPH oxidase in human PMN. We have determined the effect of changes in PA production on $\mathrm{O}_{2}$ consumption in intact PMN and the level of NADPH oxidase activity measured in a cell-free assay. Pretreatment of cells with various concentrations of propranolol enhanced $(\leq 200 \mu M)$ or inhibited $(>300$ $\mu M)$ PLD-induced production of PA (mass and radiolabel) in a manner that correlated with enhancement or inhibition of $\mathrm{O}_{2}$ consumption in PMN stimulated with $1 \mu M$ FMLP in the absence of cytochalasin $B$. The concentration-dependent effects of propranolol on FMLP-induced NADPH oxidase activation was confirmed by direct assay of the enzyme in subcellular fractions. In PA extracted from cells pretreated with $200 \mu \mathrm{M}$ propranolol before stimulation with $1 \mu$ M FMLP, phospholipase $A_{1}\left(P L A_{1}\right)$-digestion for $90 \mathrm{~min}$, followed by quantitation of residual PA, showed that a minimum of $44 \%$ of $P A$ in control (undigested) sample was diacyl-PA; alkylacyl-PA remained un-

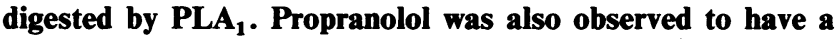
concentration-dependent enhancement of mass of 1,2-DG formed in PMN stimulated with FMLP. DG levels reached a maximum at $300 \mu \mathrm{M}$ propranolol and remained unchanged up to $500 \mu \mathrm{M}$ propranolol. However, in contrast to PA levels, the level of DG produced did not correlate with NADPH oxidase activation. Exogenously added didecanoyl-PA activated NADPH oxidase in a concentration-dependent manner (1-300 $\mu M)$ in a reconstitution assay using membrane and cytosolic fractions from unstimulated PMN. In addition, PA synergized with SDS for oxidase activation. Taken together, these results indicate that PA plays a second messenger role in the activation of NADPH oxidase in human PMN and that regulation of phospholipase $D$ is a key step in the activation pathway. ( $J$. Clin. Invest. 1991. 88:531-539.) Key words: propranolol • phospholipase D • phosphatidic acid $\bullet$ and FMLP
\end{abstract}

Address correspondence to Dr. David E. Agwu, Section on Infectious Diseases, Department of Medicine, Bowman Gray School of Medicine, 300 S. Hawthrone Road, Winston-Salem, NC 27103. S. Sozzani's current address is Instituto di Ricerche Farmacologiche "Mario Negri," via Eritrea 62, 20157 Milano, Italy.

Received for publication 4 October 1990 and in revised form 19 April 1991

J. Clin. Invest.

(c) The American Society for Clinical Investigation, Inc.

0021-9738/91/08/0531/09 \$2.00

Volume 88, August 1991, 531-539

\section{Introduction}

Stimulation of PMN with the chemotactic factor FMLP elicits several microbicidal responses including increased nonmitochondrial oxygen consumption, with generation of superoxide anion $\left(\mathrm{O}_{2}^{-}\right)$and hydrogen peroxide $\left(\mathrm{H}_{2} \mathrm{O}_{2}\right)$ (1), through the activation of a membrane-associated NADPH oxidase (2). Although the mechanisms involved in the activation of the oxidase are not completely understood, both phosphatidic acid $(\mathrm{PA})^{1}(3-5)$ and diglyceride (DG) (6-8) have been implicated.

The formation of PA and DG occurs via two major signal transduction pathways in PMN stimulated with FMLP in the presence of cytochalasin B (CB). A phosphatidylinositol 4,5bisphosphate $\left(\mathrm{PIP}_{2}\right)$-specific, guanine nucleotide regulatory protein-dependent, phospholipase C (PLC) generates DG (911) that is converted to PA by DG kinase (12). This pathway was regarded until recently as the major source of DG during cellular stimulation by receptor-mediated agonists such as FMLP. However, we $(13,14)$ and others $(15-18)$ have demonstrated that FMLP also activates a phospholipase D (PLD) that hydrolyzes choline-containing phosphoglycerides (PC) such that PA is the first metabolite formed. In this pathway, DG is generated by PA phosphohydrolase (PAP)-catalyzed dephosphorylation of PA (19). The differences in the temporal sequence of formation of PA and DG via these pathways and the fact that interconversions between these metabolites modulates their accumulation during stimulation, complicate efforts aimed at understanding the individual involvement of PA or DG in the activation of PMN NADPH oxidase.

A role for DG (6-8, 20-22) in NADPH oxidase activation has been contradicted by several lines of evidence. In intact PMN, Ohtsuka et al. (4) showed that exogenous DG did not stimulate $\mathrm{O}_{2}^{-}$production in guinea pig $\mathrm{PMN}$ and Koenderman et al. (23) reported that DG accumulation in human PMN stimulated with FMLP did not correlate with $\mathrm{O}_{2}$ consumption. Rossi and his colleagues (24-26) and Tyagi et al. (27), by inhibiting the turnover of phosphoinositides in $\mathrm{Ca}^{2+}$-depleted, FMLP-stimulated PMN, indirectly dissociated PLC-generated DG from NADPH oxidase activation. A recent report (28) using a cell-free system from human PMN showed that DG alone did not activate $\mathrm{O}_{2}^{-}$generation under conditions which were optimal for the activation of the oxidase by anionic amphiphiles and suggested that DG may play a regulatory role. In contrast, Korchak et al. (29) using radiolabeling methods correlated PA formation with $\mathrm{O}_{2}^{-}$generation in human PMN

1. Abbreviations used in this paper: $\mathrm{CB}$, cytochalasin $\mathrm{B} ; \mathrm{DG}$, diglyceride; PA, phosphatidic acid; PAP, phosphatidate phosphohydrolase; PC, choline-containing phosphoglycerides; PLC, phosphalipase C. 
stimulated with FMLP. Rossi et al. (3) using propranolol to inhibit PAP $(30,31)$, such that PLD-induced PA formation is increased while DG formation is inhibited, and butanol or ethanol to reduce the formation of PA, implicated PA as a second messenger in the activation of NADPH oxidase. In addition, our group (32) has recently reported that TNF- $\alpha$ priming followed by FMLP stimulation of human PMN leads to PA formation without an increase in the mass of DG, and that PA levels correlated with activation of the oxidase in intact cells. Further support for a second messenger effect of PA is direct evidence for the activation of NADPH oxidase by PA in intact guinea pig PMN (4) and in a cell-free system from pig PMN (5) in which cytosolic components were not required.

Despite increased research interest, however, the role of PA as a second messenger in the activation of the oxidase in human PMN stimulated with FMLP has not received general acceptance $(22,33)$ since the generation of DG from phosphoinositide hydrolysis cannot be totally eliminated even in the absence of CB $(22,33)$ and or when using pretreatment with propranolol or ethanol $(3,22,33)$. We report here that propranolol, in a concentration-dependent manner, induces an increase or a decrease in PC hydrolysis, with concomitant changes that are reflected only in the formation of PA but not DG, in human PMN stimulated with FMLP for $60 \mathrm{~s}$ in the absence of CB. We have used these differential effects of propranolol on PA and DG to study the role of PA in activation of PMN NADPH oxidase. Both the increase and decrease in PA found in human PMN in the presence of varying concentrations of propranolol correlate with activation or inhibition of NADPH oxidase. In addition, we demonstrate that PA can directly activate NADPH oxidase of human PMN in a reconstitution assay of the enzyme complex. Taken together, these results strongly support the concept that PA formed from the hydrolysis of $\mathrm{PC}$ acts as a second messenger in human PMN by regulating activation of NADPH oxidase.

\section{Methods}

Isolation and radiolabeling of human PMN. Human PMN were prepared to $>95 \%$ purity from heparinized venous blood after an initial removal of erythrocytes by dextran (Pharmacia Fine Chemicals, Uppsala, Sweden) sedimentation at unit gravity, followed by centrifugation over Isolymph (Gallard-Schlesinger Chemical Manufacturing Corp., Carle Place, NY), and hypotonic lysis of contaminating erythrocytes (1). Isolated PMNs were resuspended in HBSS (Gibco Laboratories, Grand Island, NY) containing $10 \mathrm{mM}$ Hepes, and $4.2 \mathrm{mM}$ sodium bicarbonate, $\mathrm{pH} 7.4$, at $3.5 \times 10^{7} / \mathrm{ml} .1-O-\left[9^{\prime}, 10^{\prime}-{ }^{3} \mathrm{H}_{2}\right]$ hexadecyl-2lyso-GPC $(56 \mathrm{Ci} / \mathrm{mmol})$, synthesized (34) by Jeffrey Schmitt and kindly donated by Dr. R. L. Wykle (Wake Forest University Medical Center, Winston-Salem, NC), was incorporated into PMN 1-O- $\left[{ }^{3} \mathrm{H}\right]-$ alkyl-2-acyl-GPC $\left(\left[{ }^{3} \mathrm{H}\right]\right.$ EAPC) during a 30 -min incubation period as previously described (35). The cells were washed two times and resuspended in HBSS for stimulation at a final concentration of 3.5 $\times 10^{7} / \mathrm{ml}$.

Phospholipase D assay. PLD-induced hydrolysis of $\left[{ }^{3} \mathrm{H}\right] \mathrm{EAPC}$ was determined in PMN stimulated with FMLP (Sigma Chemical Co., St. Louis, MO) in the absence of CB (Sigma Chemical Co.) as described previously (14). The effects of the following on the formation of $\left[{ }^{3} \mathrm{H}\right]-$ EAPA, $\left[{ }^{3} \mathrm{H}\right]$ EAPEt, and $\left[{ }^{3} \mathrm{H}\right] \mathrm{EAG}$ were examined: (a) propranolol dissolved in HBSS (Ayerst Labs Inc., New York, NY), which inhibits PAP $(30,31)$ so that PA accumulates; and $(b)$ ethanol, which activates the transphosphatidylation reaction to form phosphatidylethanol (PEt) $(17,18)$. PMN $\left(3.5 \times 10^{7} / \mathrm{ml}\right)$, labeled with $\left[{ }^{3} \mathrm{H}\right] \mathrm{EAPC}$, were prewarmed for $3 \mathrm{~min}$ before pretreatment, then were pretreated with or without the indicated concentrations of propranolol and/or $0.5 \%$ ethanol for $5 \mathrm{~min}$. Pretreated PMN were then stimulated with $1 \mu \mathrm{M}$ FMLP in DMSO, or given an equal volume of DMSO, for $60 \mathrm{~s}$. Both propranolol and ethanol, at the concentrations used in this study, did not affect cell viability assessed by trypan blue exclusion test. At the end of $60 \mathrm{~s}$, reactions were terminated by withdrawing samples of 2-ml aliquots into $8 \mathrm{ml}$ of chloroform/methanol/2\% formic acid (1:2:0.2, $\mathrm{vol} / \mathrm{vol}$ ) and mixing thoroughly.

Lipids analyses. Total lipids were extracted by a modification of the procedures of Bligh and Dyer (36), the organic phase was dried under a stream of $\mathrm{N}_{2}$, and lipids were resuspended in a volume of chloroform that was divided into two portions containing $1.75 \times 10^{7}$ and 5.25 $\times 10^{7}$ cell equivalents. The volume with $1.75 \times 10^{7}$ cell equivalents was dried under $\mathrm{N}_{2}$, and the lipids were resuspended in chloroform/methanol $(9: 1, \mathrm{vol} / \mathrm{vol})$ for analysis of individual lipids $\left[{ }^{3} \mathrm{H}\right]$ EAPC, $\left[{ }^{3} \mathrm{H}\right]-$ EAPA, $\left[{ }^{3} \mathrm{H}\right]$ EAPEt, and $\left[{ }^{3} \mathrm{H}\right] \mathrm{EAG}$, and determination of mass of PA. The separation of $\left[{ }^{3} \mathrm{H}\right] \mathrm{EAPC},\left[{ }^{3} \mathrm{H}\right] \mathrm{EAPA},\left[{ }^{3} \mathrm{H}\right] \mathrm{EAPEt}$, and $\left[{ }^{3} \mathrm{H}\right] \mathrm{EAG}$ by TLC was accomplished in solvent system (I) made up of the organic phase of ethyl acetate/iso-octane/glacial acetic acid/ $\mathrm{H}_{2} \mathrm{O}$ (110:50:20:100, vol/vol) on Silica Gel-60 plates (E. Merck, Darmstadt, FRG). Identification of these individual lipids and chemical analyses have been previously described (14). The separation and percentage distribution of $\left[{ }^{3} \mathrm{H}\right] \mathrm{EAPC}$ and $\left[{ }^{3} \mathrm{H}\right] \mathrm{EAPA}$ were further confirmed in solvent system (II) containing chloroform/methanol/glacial acetic acid/ $\mathrm{H}_{2} \mathrm{O}$ (75:48:12.5:3.5, vol/vol), following scraping of plates and liquid scintillation counting. The fraction of lipid extracts containing $5.25 \times 10^{7}$ cell equivalents was used for the separation of neutral lipids in solvent system (III) made up of chloroform/methanol/glacial acetic acid (98:2:1, vol/vol) and to quantitate mass of 1,2-DG.

Determination of mass of $P A$ and 1,2-DG. The masses of PA and 1,2-DG were determined by methods we have previously described (13), following separation of lipid extracts obtained from $1.75 \times 10^{7}$ and $5.25 \times 10^{7}$ cell equivalents, in solvent system I and III, respectively. Briefly, separated lipids including their standards (1-palmitoyl-2oleoyl-PA (Avanti Polar Lipids, Birmingham, AL) and 1,2-diglyceride (Serdary Research Laboratories, London, Ont. Canada)) were stained with 0.03\% Coomassie brilliant blue R-250 (CBB R-250) (Bio-Rad Laboratories, Richmond, CA) in $30 \%$ methanol containing $100 \mathrm{mM} \mathrm{NaCl}$ for $30 \mathrm{~min}$. The TLC plates were partially destained with $30 \%$ methanol containing $100 \mathrm{mM} \mathrm{NaCl}$, air-dried, and the PA or 1,2-DG bands, including standard lipids, were scanned with a laser densitometer (LKB 2400 Ultroscan XL; LKB Instruments, Inc., Gaithersburg, MD) at a wavelength of $633 \mathrm{~nm}$ to obtain area values. Masses of PA and 1,2-DG were determined from standard curves of areas of known masses of lipid standards. By these methods, $>95 \%$ of $\left[{ }^{3} \mathrm{H}\right]$-radiolabel was recovered in PA or EAG, suggesting no losses due to CBB R-250 staining procedures (13).

Determination of diacyl-and alkylacyl-content of $P A$. The possibility that phospholipids other than the ether-linked species of PC may contribute to PA generated in cells stimulated with FMLP was investigated. $2 \mathrm{ml}$ of PMN $\left(3.5 \times 10^{7}\right.$ cells $\left./ \mathrm{ml}\right)$, prelabeled with $\left[{ }^{3} \mathrm{H}\right] \mathrm{EAPC}$ and pretreated with $200 \mu \mathrm{M}$ propranolol for $5 \mathrm{~min}$ at $37^{\circ} \mathrm{C}$, was stimulated with $1 \mu \mathrm{M}$ FMLP for $60 \mathrm{~s}$. After termination of the reaction, the organic solvent containing extracted lipids was divided into two equal aliquots based on $\left[{ }^{3} \mathrm{H}\right]$-dpm content. The lipids were separated in solvent system I and PA was identified, scraped off the plate, and eluted from silica gel with two volumes of $3 \mathrm{ml}$ of methanol/chloroform $/ \mathrm{H}_{2} \mathrm{O}$ (10:25:5, vol/vol). After drying off organic solvents under $N_{2}$, PA in 1 -ml cell equivalents was subjected to digestion by phospholipase $A_{1}$ $\left(\right.$ PLA $_{1}$ ) (Rhizopus arrhizus; Boehringer Mannheim Biochemicals, Indianapolis, IN) by a modification of the methods of Tamer et al. (37).

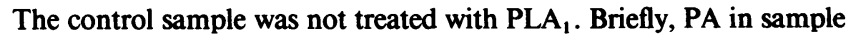
and control tubes was resuspended and vortexed in $0.5 \mathrm{ml}$ of diethyl ether/methanol $(95: 5, \mathrm{vol} / \mathrm{vol})$ and 1,000 U of PLA $\mathrm{A}_{1}$ in $100 \mu \mathrm{l}$ of a buffer (containing $220 \mathrm{mM} \mathrm{NaCl}, 50 \mathrm{mM}$ Tris- $\mathrm{HCl}, 20 \mathrm{mM} \mathrm{CaCl}_{2}, 1$ mM EDTA, pH 7.4 [38]) was added into the sample tube; an equivalent volume of buffer alone was added to the control tube. After mixing both tubes vigorously for $30 \mathrm{~s}$, incubation was conducted for $90 \mathrm{~min}$ at 
room temperature with mixing. The reaction was terminated by drying off the ether under $\mathrm{N}_{2}$ and lipids were extracted by the methods of Bligh and Dyer (36), separated in solvent system II and stained with CBB R-250 (14). The mass of PA and the $\left[{ }^{3} \mathrm{H}\right]-\mathrm{dpm}$ content, in control and PLA $_{1}$-treated samples, was quantitated and compared as previously described (13 and above).

Subcellular fractionation of PMN. Separation of cytosolic, granule, and membrane fractions from unstimulated or stimulated PMN was conducted on a discontinuous sucrose gradient by methods previously described (38). Briefly, unlabeled unstimulated PMN, or PMN that had been stimulated with FMLP for $60 \mathrm{~s}$ in the presence or absence of propranolol, as described above, were resuspended at $10^{8} / \mathrm{ml}$ in a sonication buffer (containing $11 \% \mathrm{wt} / \mathrm{vol}$ sucrose; $130 \mathrm{mM} \mathrm{NaCl} ; 1 \mathrm{mM}$ EGTA; 0.5 mM PMSF, pH 7.0), and were disrupted by sonication in $1-\mathrm{ml}$ aliquots. Sonicates were centrifuged at $800 \mathrm{~g}$ for $10 \mathrm{~min}$ at $4^{\circ} \mathrm{C}$ and subcellular fractionation was performed by layering the supernatants in the $11 \%$ sucrose buffer over a 15 and $40 \%$ (wt/vol) sucrose gradient to achieve a final ratio of $2: 1: 1$ (vol/vol) of 11,15 , and $40 \%$, respectively. Gradients were centrifuged at $150,000 \mathrm{~g}$ for $30 \mathrm{~min}$ at $4^{\circ} \mathrm{C}$ after which the top layer (cytosol) was collected and centrifuged at $150,000 \mathrm{~g}$ for an additional $60 \mathrm{~min}$ in order to pellet contaminating particulate material and obtain a cleared cytosol. The membrane fraction was collected at the $15 / 40 \%$ interface, and included the $40 \%$ layer, of each discontinuous gradient. The granule fractions (pellets) were resuspended in sonication buffer to a cell equivalence of $2 \times 10^{8} / \mathrm{ml}$. Fractions were stored at $-70^{\circ} \mathrm{C}$ until assays were performed and were stable for several months.

NADPH oxidase activity in particulate fractions from stimulated $P M N$. NADPH oxidase activity (the NADPH-dependent, superoxide dismutase-inhibitable reduction of cytochrome $c$ ) was measured as previously described $(2,39)$ with minor modifications. Briefly, the assay mixture consisted of $48 \mathrm{mM}$ potassium phosphate ( $\mathrm{pH} 7.0$ ), $76 \mu \mathrm{M}$ cytochrome $c$ (type III), $1.0 \mathrm{mM}$ EGTA, $10 \mu \mathrm{M}$ flavin adenine nucleotide (all from Sigma Chemical Co.), $7.5 \mathrm{mM} \mathrm{MgCl}, 2.5 \mu \mathrm{M} \mathrm{Al}_{2}\left(\mathrm{SO}_{4}\right)_{3}$, $10 \mathrm{mM} \mathrm{NaF}$, and membrane or granule fraction at a cell equivalence of $1.6 \times 10^{6} / \mathrm{ml}$. Aliquots of assay mixture were placed in two cuvettes: the reference cuvette containing $48 \mu \mathrm{g} / \mathrm{ml}$ superoxide dismutase (Diagnostic Data, Inc., Mountain View, CA) and sample cuvette containing $\mathrm{H}_{2} \mathrm{O}$. NADPH oxidase activity was measured following the addition of 0.19 mM NADPH (Boehringer Mannheim Biochemicals) to both cuvettes, as the change in absorbance at $550 \mathrm{~nm}$ recorded by a dual beam spectrophotometer (Cary 2390; Varian Instruments, Sunnyvale, CA). Initial rates were used for calculations and activity was expressed as $\mathrm{nmol} / \mathrm{min} / \mathrm{mg}$ particulate protein (40) using an extinction coefficient of $21 \mathrm{mM}^{-1} \mathrm{~cm}^{-1}$ for cytochrome $c(41)$. After cell stimulation, activity was distributed between membrane and granule fractions and, for the sake of simplicity, these activities were combined. In addition, inclusion of $150 \mu \mathrm{M}$ SDS (Bio-Rad Laboratories) in the assay (in the absence of cytosolic fractions) resulted in an approximate doubling of activity, with no change in the pattern observed. Since measured activities were higher in the presence of SDS, this detergent was routinely included in all assays of NADPH oxidase activity in particulate fractions from stimulated cells (data reported in Fig. 7).

Activation of NADPH oxidase induced by PA in a cell-free system. The activation of NADPH oxidase by various PAs (dimyristoyl and distearoyl from Avanti Polar Lipids; dipalmitoyl, didecanoyl, and dioleoyl from Serdary Research Laboratories; and egg lecithin from Sigma Chemical Co.) was investigated in a cell-free system by a modifcation of the procedures described previously $(39,42)$ and above. The ability of PA to activate NADPH oxidase was tested both alone and in combination with a suboptimal concentration of SDS $(50 \mu \mathrm{M})$. PAs were prepared freshly in $\mathrm{H}_{2} \mathrm{O}$ by sonication. Membrane and cytosolic fractions derived from subcellular fractionation of unstimulated PMNs were mixed, at a final concentration of $1.6 \times 10^{6}$ cell equivalents $/ \mathrm{ml}$ for each fraction, with other assay components $(48 \mathrm{mM}$ potassium phosphate [pH 7.0], $76 \mu \mathrm{M}$ cytochrome $c, 1.0 \mathrm{mM}$ EGTA, $10 \mu \mathrm{M}$ flavin adenine nucleotide, $7.5 \mathrm{mM} \mathrm{MgCl}_{2}, 2.5 \mu \mathrm{M} \mathrm{Al}_{2}\left[\mathrm{SO}_{4}\right]_{3}, 10 \mathrm{mM} \mathrm{NaF}$ ) and various concentrations of the desired PA in the presence or absence of $50 \mu \mathrm{M}$ SDS. Reaction mixtures were preincubated at room temperature for $6 \mathrm{~min}$ in order to achieve maximum activation of NADPH oxidase before addition of NADPH and measurement of the change in absorbance at $550 \mathrm{~nm}$, as described above.

Measurement of oxygen consumption. Oxygen consumption by PMNs prewarmed for 5 min was measured with a Clark-type oxygen electrode (Yellow Springs Instruments, Yellow Springs, $\mathrm{OH}$ ) using a homemade nanoammeter (8). Briefly, assays were conducted at $37^{\circ} \mathrm{C}$ in the presence of $2 \mathrm{mM} \mathrm{NaN}_{3}$ with $\mathrm{PMN}$ at a final concentration of 3.5 $\times 10^{7}$ cells/ml. FMLP, at a final concentration of $100 \mathrm{nM}$, was injected into the chamber with a Hamilton syringe after a 5-min preincubation of cells with various concentrations of propranolol in the absence of
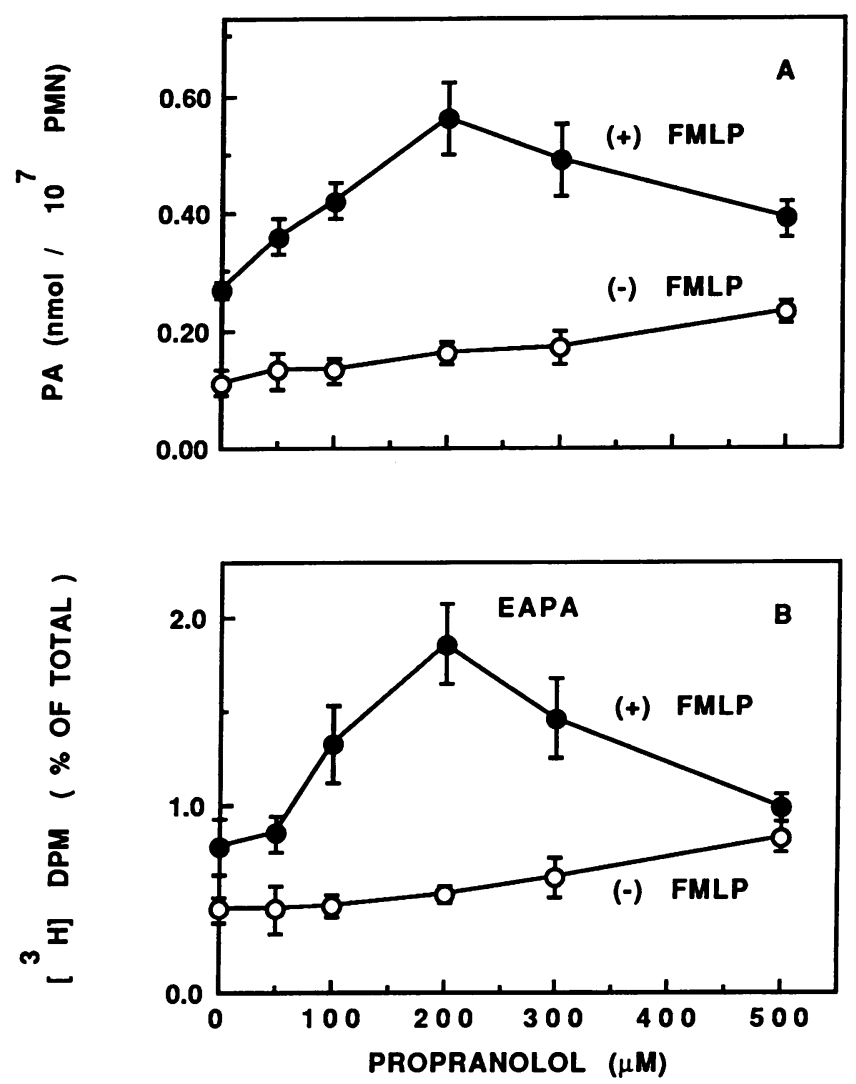

Figure 1. Effects of various concentrations of propranolol on the accumulation (mass) of phosphatidic acid $(A)$ and formation of $\left[{ }^{3} \mathrm{H}\right]-$ EAPA $(B)$ in PMN-stimulated with FMLP in the absence of cytochalasin B. Human PMN $\left(3.5 \times 10^{7} / \mathrm{ml}\right)$ labeled with $\left[{ }^{3} \mathrm{H}\right] \mathrm{EAPC}$ were incubated with the indicated concentrations of propranolol for $5 \mathrm{~min}$ before addition of $1 \mu \mathrm{M}$ FMLP in DMSO solvent, or an equal volume of DMSO in unstimulated controls. At the end of $60 \mathrm{~s}$ after addition of FMLP, reactions were terminated and total lipids were extracted. A fraction of the lipid extracts $\left(0.5 \mathrm{ml}\right.$ or $1.75 \times 10^{7}$ cell equivalents) and PA standards of known mass were subjected to TLC in solvent system (I) to separate individual lipids. $(A)$ Plates were stained with CBB R-250 and PA was quantitated in stimulated (๑) and control (O) samples as described in Methods. $(B)$ The individual lanes on TLC plates were scanned for radioactivity with a Bioscanner (Imagining Scanner 200-IBM, Washington, DC) to identify locations of $\left[{ }^{3} \mathrm{H}\right]-$ EAPC, $\left[{ }^{3} \mathrm{H}\right]$ EAPA, and $\left[{ }^{3} \mathrm{H}\right]$ EAG. Calculation of percentage distribution of ${ }^{3} \mathrm{H}$-label in individual lipid fractions was performed for stimulated (๑) and control (O) samples after scraping of bands and liquid scintillation counting (see Methods). Data represent the mean $\pm S E$ for four experiments except for experiments conducted in the presence of 50 and $100 \mu \mathrm{M}$ propranolol, which represent the mean $\pm \mathrm{SE}$ for three separate experiments. 

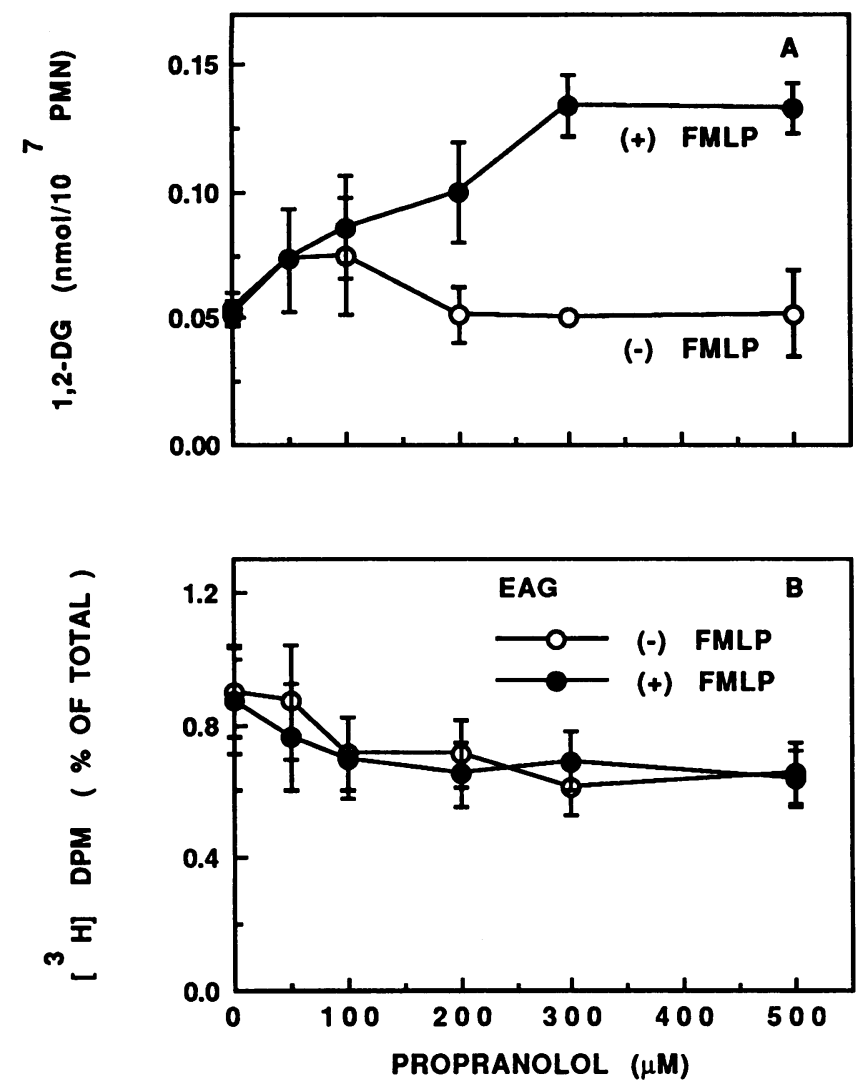

Figure 2. Effect of various concentrations of propranolol on the accumulation of 1,2-DG $(A)$ and formation of $\left[{ }^{3} \mathrm{H}\right] \mathrm{EAG}(B)$ in PMN stimulated with FMLP. Human PMN $\left(3.5 \times 10^{7} / \mathrm{ml}\right)$ labeled with $\left[{ }^{3} \mathrm{H}\right]$ EAPC, were treated as described in Fig. 1. $(A)$ Lipid extracts containing $5.25 \times 10^{7}$ cell equivalents were separated in solvent system III along with known masses of 1,2-DG and EAG standards. The mass of 1,2-DG was quantitated in stimulated (๑) and control (0) samples following staining of lipids with CBB R-250 and densitometry of samples and standards as described in Methods. Data represent the mean $\pm S E$ from four experiments, except for values at 50 and $100 \mu \mathrm{M}$ propranolol, which represent the mean \pm SE for three separate experiments. $(B)$ Lipid extracts containing $1.75 \times 10^{7}$ cell equivalent were developed in solvent system $I$ and the percentage distribution of $\left[{ }^{3} \mathrm{H}\right]$-label in EAG was determined from stimulated (•) and control (o) samples. Data represent the mean $\pm \mathrm{SE}$ for four experiments except for values at 50 and $100 \mu \mathrm{M}$ propranolol, which represent the mean $\pm \mathrm{SE}$ for three separate experiments.

CB. Initial slopes after the addition of FMLP were used for calculations.

\section{Results}

Differential effects of propranolol on formation of $P A$ and $D G$. To investigate the effect of various concentrations of propranolol on the generation of PLD-derived products, PA and DG, and to examine correlations between PA and/or DG and the activation of NADPH oxidase, the formation of these metabolites was determined in $\left[{ }^{3} \mathrm{H}\right] \mathrm{EAPC}$-labeled PMN stimulated with FMLP in the absence of CB. A differential effect of increasing concentrations of propranolol on FMLP-induced generation of PA was demonstrated by an enhancement (at concentrations $\leq 200 \mu \mathrm{M}$ ) or inhibition (at concentrations $\geq 300$ $\mu \mathrm{M}$ ) of PA levels as determined by both mass quantitation (Fig. $1 \mathrm{~A}$ ) and radiolabeling (Fig. $1 \mathrm{~B}$ ) methods. Results obtained by both methods are in close agreement. In the absence of FMLP, there was a slight increase in PA with increasing concentrations of propranolol.

As shown in Fig. 2, the dose-dependent effect of propranolol on the accumulation (mass) of 1,2-DG and on the formation of $\left[{ }^{3} \mathrm{H}\right] \mathrm{EAPG}$ at $60 \mathrm{~s}$ following stimulation with FMLP was strikingly different in two ways from results obtained with respect to PA. First, the mass of 1,2-DG generated increased with increasing concentrations of propranolol in PMN stimu-
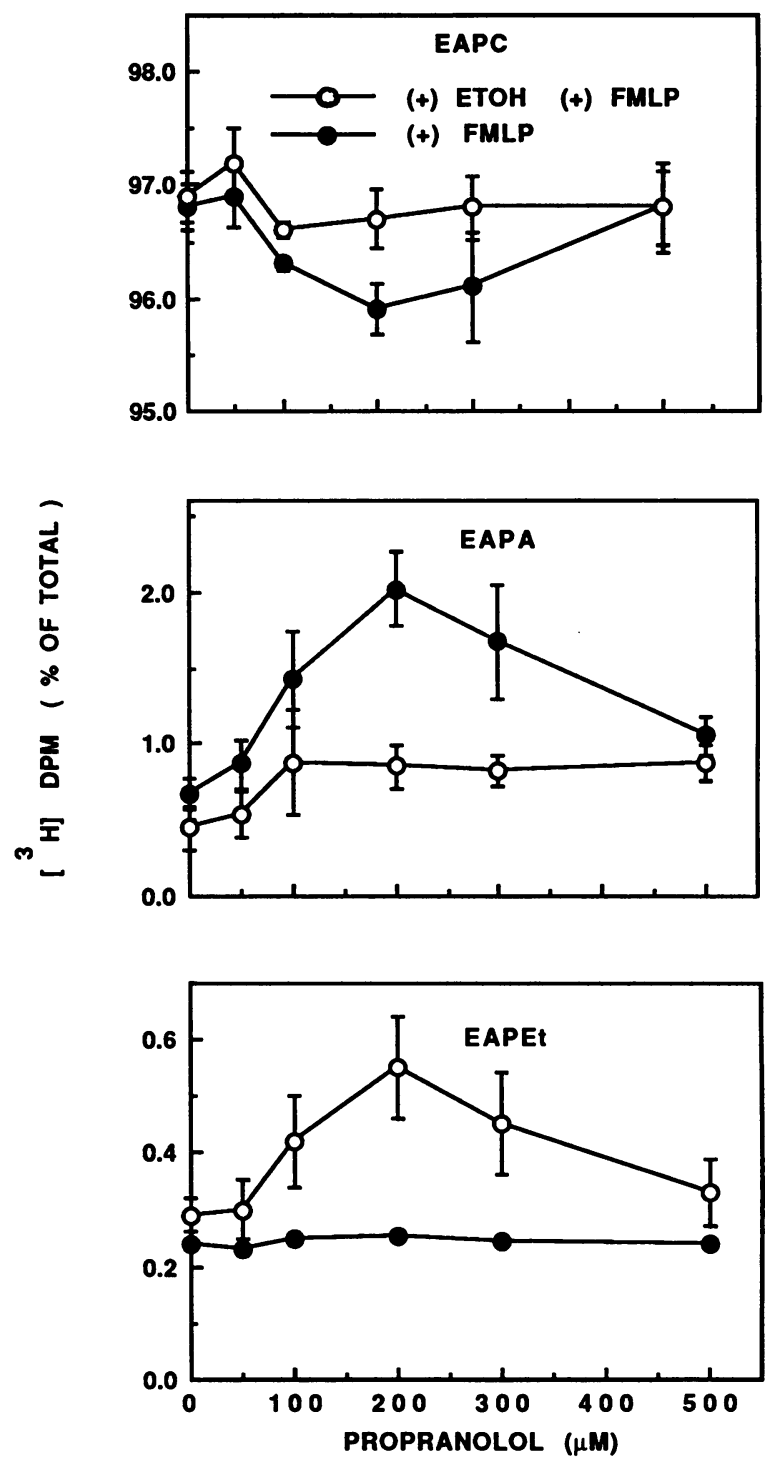

Figure 3. Effect of various concentrations of propranolol on FMLPinduced breakdown of $\left[{ }^{3} \mathrm{H}\right] \mathrm{EAPC}(A)$ and formation of $\left[{ }^{3} \mathrm{H}\right] \mathrm{EAPA}$ $(B)$ and $\left[{ }^{3} \mathrm{H}\right]$ EAPEt $(C)$. PMN $\left(3.5 \times 10^{7} / \mathrm{ml}\right)$ were labeled and pretreated with (O) or without $(\bullet) 0.5 \%$ ethanol and the indicated concentrations of propranolol, for $5 \mathrm{~min}$, before stimulation with $1 \mu \mathrm{M}$ FMLP, for $60 \mathrm{~s}$, in the absence of cytochalasin B. Termination of reactions, lipid extraction, separation, and analysis of individual lipid fractions, $\left[{ }^{3} \mathrm{H}\right]$ EAPC, $\left[{ }^{3} \mathrm{H}\right]$ EAPA, and $\left[{ }^{3} \mathrm{H}\right]$ EAPEt from samples containing $1.75 \times 10^{7}$ cell equivalents were conducted as described for Fig. 1 and in Methods. Data represent the mean \pm SE for three separate experiments. 
lated with FMLP. This observation is in agreement with an earlier report that propranolol stimulates the hydrolysis of phosphoinositides to generate DG (43), which is enhanced in the presence of FMLP (Fig. $2 A$ ). At $300 \mu \mathrm{M}$, mass of 1,2-DG reached a maximum and remained unchanged up to $500 \mu \mathrm{M}$ propranolol. At $500 \mu \mathrm{M}$ propranolol, PA levels had declined. Second, in contrast to $\left[{ }^{3} \mathrm{H}\right] \mathrm{EAPA}$, the level of $\left[{ }^{3} \mathrm{H}\right] \mathrm{EAG}$ in the presence or absence of FMLP declined with increasing concentrations of propranolol, presumably due to inhibition of PAP $(30,31)$.

To account for the enhancement and inhibition of PA formation in the presence of varying concentrations of propranolol (Fig. 1), we examined the concentration-dependent effect of propranolol on the hydrolysis of $\left[{ }^{3} \mathrm{H}\right] \mathrm{EAPC}$ by PLD. We also investigated the possibility that propranolol might have a direct effect on the activation of PLD by studying its effect on the PLD-specific transphosphatidylation reaction in cells pretreated with $0.5 \%$ ethanol. Results in Fig. 3 show that FMLP induces the hydrolysis of $\left[{ }^{3} \mathrm{H}\right] \mathrm{EAPC}$, and that propranolol at concentrations up to $200 \mu \mathrm{M}$ enhances the formation of $\left[{ }^{3} \mathrm{H}\right]-$ EAPA presumably through the inhibition of PAP and also through the enhancement of PLD-induced hydrolysis of $\left[{ }^{3} \mathrm{H}\right]-$ EAPC. At concentrations of propranolol $\geq 300 \mu \mathrm{M}$, especially at $500 \mu \mathrm{M}$, our results show an inhibition of both [ $\left.{ }^{3} \mathrm{H}\right] \mathrm{EAPC}$ hydrolysis and $\left[{ }^{3} \mathrm{H}\right] \mathrm{EAPA}$ formation, both of which suggest an inhibition of PLD activity. Since the formation of $\left[{ }^{3} \mathrm{H}\right] \mathrm{EAPEt}$ is an indirect measure of PLD activity, its formation in cells stimulated with FMLP was examined as the concentration of propranolol increased. As shown in Fig. 3, the hydrolysis of $\left[{ }^{3} \mathrm{H}\right]$ EAPC by FMLP was inhibited in the presence of ethanol at concentrations of propranolol $>200 \mu \mathrm{M}$. Despite this inhibi- tion, a biphasic increase ( $\leq 200 \mu \mathrm{M}$ propranolol) and decrease $(\geq 300 \mu \mathrm{M})$ in $\left[{ }^{3} \mathrm{H}\right] \mathrm{EAPEt}$ formation was observed that correlated with the generation of $\left[{ }^{3} \mathrm{H}\right] \mathrm{EAPA}$ in the absence of ethanol. These results indicate that, $(a)$ the PC-PLD pathway contributes to PA formation in human PMN stimulated with FMLP in the absence of CB, $(b)$ the transphosphatidytation reaction may used to reduce the accumulation of PA, and $(c)$ propranolol may, in a dose-dependent manner, have a direct effect on the activation of PLD and/or PLD activity in PMN stimulated with FMLP.

Since the PA may be derived from phospholipids other than the ether-linked species of PC (44), we investigated the composition of PA formed in cells pretreated with $200 \mu \mathrm{M}$ propranolol before stimulation with FMLP. As shown in Fig. 4 , digestion of PA-containing $\left[{ }^{3} \mathrm{H}\right] \mathrm{EAPA}$ with phospholipase $A_{1}\left(P_{1} A_{1}\right)$, which hydrolyzes acyl-but not alkyl-linked fatty acids in the $s n-1$ position, resulted in a reduced PA content and increased lyso-PA formation compared with undigested controls. Despite the $\mathrm{PLA}_{1}$ digestion, the $\left[{ }^{3} \mathrm{H}\right]-\mathrm{dpm}$ in PA remained unchanged $(4,355 \mathrm{dpm}$ after PLA treatment vs. 4,770 $\mathrm{dpm}$ in control samples), indicating that EAPA was formed but not hydrolyzed. Mass measurement (see Methods) indicated that the minimum diacyl-PA content of total PA formed was 44\% following digestion with PLA $_{1}$ for 90 min. Similar studies in the absence of propranolol show that both diacyl-and alkylacyl-PA were formed in PMN stimulated with FMLP in the absence of CB (results not shown).

Differential effects of propranolol on the activation of NADPH oxidase. The concentration of PMNs chosen to study the effect of propranolol on FMLP-induced activation of NADPH oxidase was based on results shown in Fig. 5. The

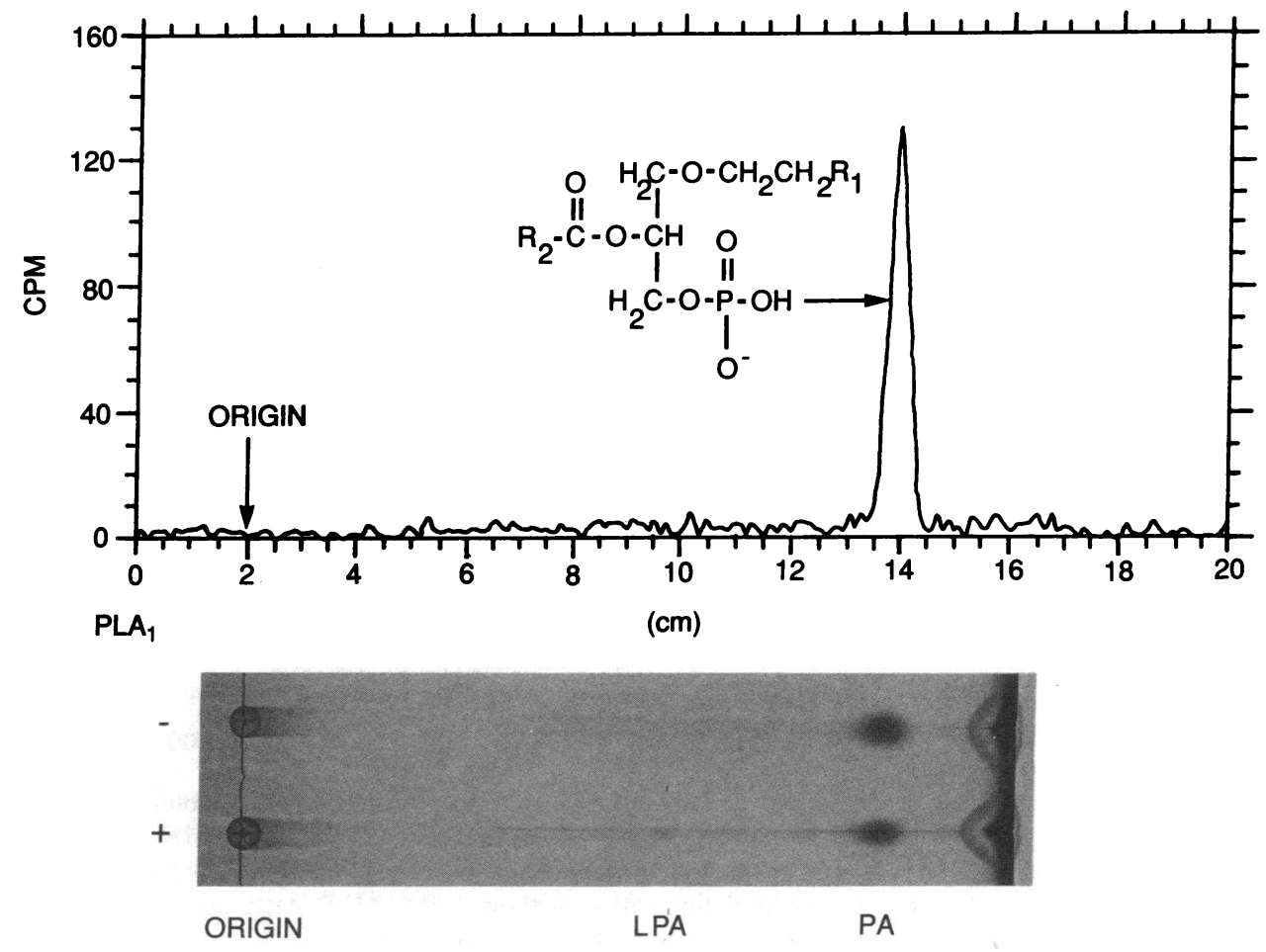

Figure 4. Determination of diacyland alkylacyl-content of PA by digestion with PLA (Rhizopus lipase). Cellular lipids in $2 \mathrm{ml}$ of PMN (3.5 $\times 10^{7} / \mathrm{ml}$ ) labeled with $\left[{ }^{3} \mathrm{H}\right]$ EAPC and pretreated with $200 \mu \mathrm{M}$ propranolol before stimulation with 1 $\mu \mathrm{M}$ FMLP for $60 \mathrm{~s}$ were extracted, and separated in solvent system $I$ as described in Methods. The silica gel region containing PA was scraped, eluted, and divided into two aliquots containing equivalent $\left[{ }^{3} \mathrm{H}\right]-\mathrm{dpm}$. PA in one sample was subjected to PLA treatment for $90 \mathrm{~min}$ (bottom panel, + ), while controls were incubated with buffer for the same period of time (bottom panel, -). After extraction of lipids and separation in solvent system II, both PA and lyso-PA were identified and stained with CBB R-250. The sample and control lanes on the TLC plate were scanned to locate the position of the $\left[{ }^{3} \mathrm{H}\right]-\mathrm{ra}-$ diolabel. The scan of the sample treated with PLA $_{1}$ is shown in the top panel. After quantitating the PA mass in control samples and the residual PA in PLA 1 -treated samples,

the regions containing the PAs were scraped off and counted. Control sample contained 4,355 dpm compared with 4,770 dpm in PLA samples. The loss of mass due to the PLA $A_{1}$ treatment in this experiment was estimated to be $38 \%$. The results represent one of two separate experiments. 


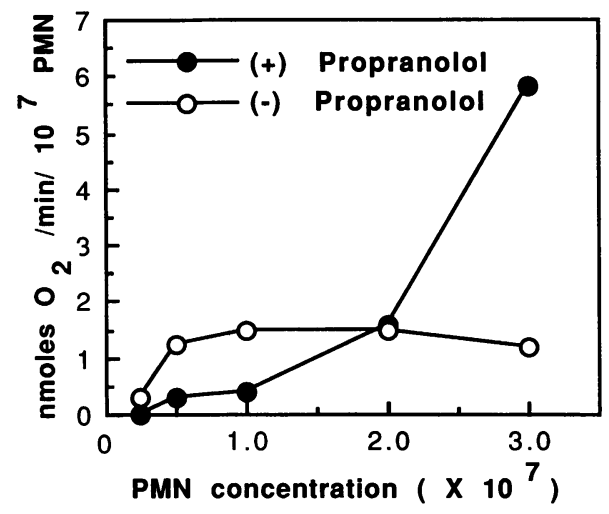

Figure 5. Effect of propranolol on $\mathrm{O}_{2}$ consumption stimulated by FMLP determined at various concentrations of PMN. The rate of $\mathrm{O}_{2}$ consumption was determined at the indicated concentrations of PMN preincubated for $5 \mathrm{~min}$ in the presence or absence of $250 \mu \mathrm{M}$ propranolol before stimulation with $100 \mathrm{nM}$ FMLP, as described in Methods. Initial rate of $\mathrm{O}_{2}$ consumption was expressed as nmoles $\mathrm{O}_{2} / \mathrm{min} / 10^{7} \mathrm{PMN}$ for one representative experiment of three performed.

effect of $250 \mu \mathrm{M}$ propranolol on the rate of $\mathrm{O}_{2}$ consumption was dependent on the concentration of intact PMNs. At cell concentrations $<2.0 \times 10^{7} / \mathrm{ml}, 250 \mu \mathrm{M}$ propranolol inhibited $\mathrm{O}_{2}$ consumption, while an enhancement was observed above this concentration. By increasing cell concentration, the inhibitory effect of propranolol is diluted. All subsequent studies were, therefore, conducted at $3.5 \times 10^{7} \mathrm{PMN} / \mathrm{ml}$, the same concentration of cells at which PLD-derived metabolites were examined.

The effect of varying concentrations of propranolol on the rate of oxygen consumption is shown in Fig. 6. In the presence of 50-250 $\mu \mathrm{M}$ propranolol, the rate of $\mathrm{O}_{2}$ consumption was enhanced in intact PMN stimulated with 100 nM FMLP compared with control cells untreated with propranolol. However, at $500 \mu \mathrm{M}$ propranolol, a marked inhibition of $\mathrm{O}_{2}$ consump-

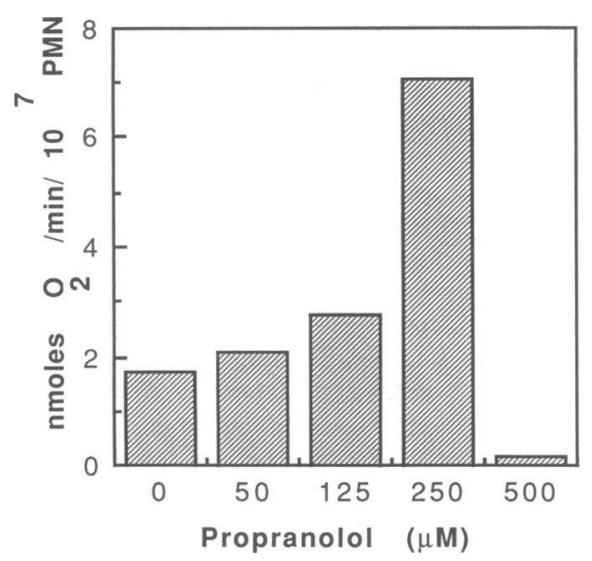

Figure 6. Effect of various concentrations of propranolol on $\mathrm{O}_{2}$ consumption in PMN stimulated with FMLP. PMN $\left(3.5 \times 10^{7} / \mathrm{ml}\right)$ were incubated with the indicated concentration of propranolol prior to stimulation with $100 \mathrm{nM}$ FMLP. The initial rate of $\mathrm{O}_{2}$ consumption in response to FMLP was measured as described in Methods and expressed as nanomoles $\mathrm{O}_{2} / \mathrm{min} / 10^{7} \mathrm{PMN}$. Data represent one experiment of two performed. tion was observed. This concentration of propranolol did not affect PMN viability, as determined by exclusion of trypan blue dye. These results were confirmed in a direct assay of NADPH oxidase activity, measured in combined membrane and granule fractions as shown in Fig. 7. Again, propranolol induced a dose-dependent enhancement or inhibition of NADPH oxidase activity in FMLP-stimulated PMN. Linear regression analyses indicate a positive correlation between PA generation (Fig. $1, A$ and $B$ ), as measured by mass $(r=0.856)$ or $\left[{ }^{3} \mathrm{H}\right]$ EAPA $\left.(r=0.857)\right)$, and NADPH oxidase activity in the cell-free assay (Fig. 7). No correlation $(r=0.0826)$ between 1,2-DG (Fig. $2 \mathrm{~A}$ ) and NADPH oxidase activity (Fig. 7) was found. In additional studies conducted in tandem (results not shown), $\mathrm{O}_{2}$ consumption was determined and compared with PA and DG formation in cells pretreated with $200 \mu \mathrm{M}$ propranolol in the presence or absence of $0.5 \%$ ethanol before stimulation with FMLP. Our results were in agreement with previous studies (3), and with results in Fig. 3, showing that ethanol treatment induced the formation of $\left[{ }^{3} \mathrm{H}\right] \mathrm{EAPEt}$ such that PA formation (mass and radiolabel) was reduced. $\mathrm{O}_{2}$ consumption was also reduced. However, 1,2-DG mass remained unchanged. Taken together these results suggest a direct role for PA in the activation NADPH oxidase but do not exclude the involvement 1,2-DG.

Didecanoyl-PA activates NADPH oxidase. To directly test if PA could modulate activation of NADPH oxidase, we examined the activation of the enzyme complex in a reconstitution assay using membrane and cytosolic fractions prepared from unstimulated PMN. The effect of didecanoyl PA was tested alone and in the presence of a suboptimal concentration of the amphiphilic activator SDS. As shown in Table I, didecanoylPA alone induced a modest activation of NADPH oxidase at

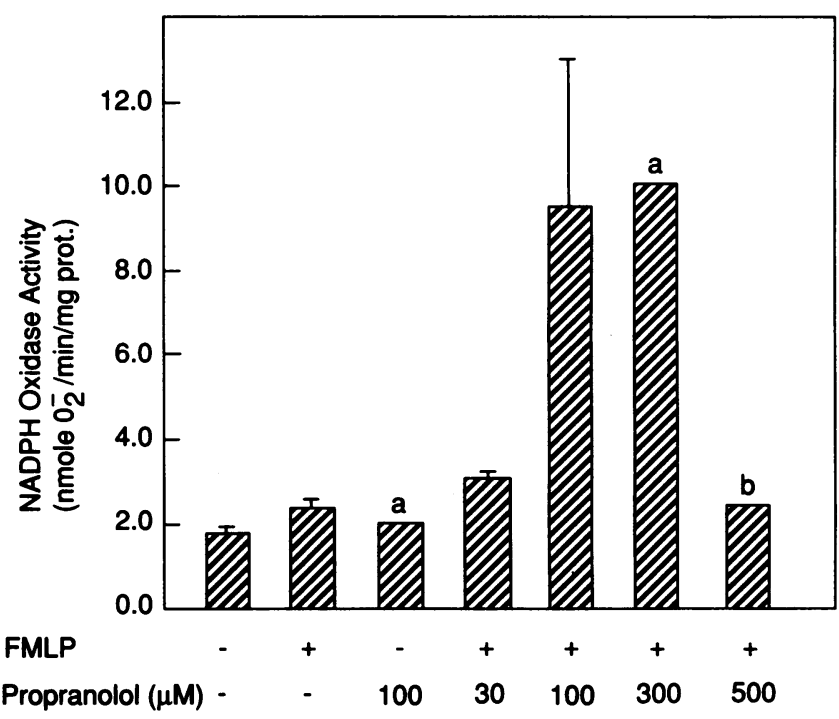

Figure 7. Effect of various concentrations of propranolol on the stimulation of NADPH oxidase activity by FMLP. PMN $\left(3.5 \times 10^{7} /\right.$ $\mathrm{ml}$ ) were treated with indicated concentrations of propranolol prior to stimulation with or without $1 \mu \mathrm{M}$ FMLP. After a 60-s stimulation period, subcellular fractionation of cells was performed and NADPH oxidase activity was determined in membrane and granule fractions as described in Methods. Data are the mean $\pm S E$ of three experiments except for $a$, which is the average of two separate experiments, and $b$, which is from one experiment. 
Table I. Effect of Various Concentrations of didecanoyl-PA on the Cell-free Activation of NADPH Oxidase

\begin{tabular}{|c|c|c|}
\hline \multirow[b]{2}{*}{ Didecanoyl-PA $(\mu \mathrm{M})^{\ddagger}$} & \multicolumn{2}{|c|}{ NADPH oxidase activity* } \\
\hline & $(-)$ SDS $^{\ddagger}$ & (+) $\mathrm{SDS}^{\ddagger}$ \\
\hline & \multicolumn{2}{|c|}{$\mathrm{nmol} O_{2}^{-} / \mathrm{min} / \mathrm{mg}$ protein } \\
\hline 0 & $1.2 \pm 0.2(5)$ & $14.2 \pm 2.2(5)$ \\
\hline 1 & $1.5(1)$ & $21.1 \pm 4.3(3)$ \\
\hline 10 & $4.5(1)$ & $29.0 \pm 4.9(3)$ \\
\hline 100 & $4.5 \pm 0.9(5)$ & $28.3 \pm 3.1(5)$ \\
\hline 300 & $4.5 \pm 0.8(3)$ & $28.6 \pm 6.8(3)$ \\
\hline 1000 & $2.9 \pm 0.6(3)$ & $10.6 \pm 2.5(3)$ \\
\hline
\end{tabular}

* NADPH oxidase activity was measured in mixtures of cytosolic and membrane fractions from unstimulated PMN after a 6-min preincubation, as described in Methods. Assays were performed in duplicate or triplicate, and results were averaged for each condition in each experiment. Values are given as the mean \pm SEM, with the number of separate experiments performed indicated in parentheses.

‡ Assays were performed in the presence or absence of $50 \mu \mathrm{m}$ SDS, with the addition of the indicated concentration of didecanoyl-PA.

concentrations ranging from 10 to $300 \mu \mathrm{M}$. Activation decreased slightly at $1,000 \mu \mathrm{M}$. In the presence of SDS, didecanoyl-PA induced a synergistic increase in NADPH oxidase activation. Synergy was observed at the lowest concentration tested $(1 \mu \mathrm{M})$, was maximum at $10-300 \mu \mathrm{M}$, and declined sharply at $1,000 \mu \mathrm{M}$. In additional experiments, the effects of the other molecular species of PA were variable. Whereas certain PAs (egg lecithin, dioleoyl [18:1]) activated the oxidase in the absence of SDS, other PAs (dimyristoyl [14:0], dipalmitoyl [16:0], distearoyl [18:0]) did not (results not shown). However, all PAs synergized to varying extents with SDS to enhance the activation of NADPH oxidase (10:0 $>>$ egg $=18: 1>16: 0=14: 0$ $=18: 0$ ). This result indicates that, depending on its fatty acid composition, exogenously added PA can directly activate human PMN NADPH oxidase. Since studies in intact PMN have suggested the involvement of DG in the activation of the oxidase $(6-8,21)$, we also investigated the effect of dioctanoylglycerol (diC8) in the cell-free assay. We observed that diC8 had no effect alone, but also synergized with SDS (results not shown) to activate NADPH oxidase, confirming a recent report (28).

\section{Discussion}

Our earlier studies of PC metabolism $(13,14)$ prompted us to examine the role of PA as a second messenger in PMN stimulated with FMLP in the absence of CB. By this approach, the role of PA and/or DG in the activation of NADPH oxidase was investigated by avoiding the enhancement of superoxide generation and phospholipid (phosphoinositides and PC) metabolism $(13,14,17,29,44,45)$ observed in the presence of CB. Although PLC-induced hydrolysis of $\mathrm{PIP}_{2}$ has been considered the pathway for the formation of DG and PA in the absence of CB (44), our results show that PC is hydrolyzed by PLD and that the PA generated is a second messenger in activation of NADPH oxidase, an enzyme critically important in generating one of the microbicidal mechanisms of PMN (1). Our results also demonstrate the importance of PLD in regulating functional responses of human PMN.
These conclusions are based on the following three observations: First, the elevation or depression in mass of PA (Fig. $1 \mathrm{~A}$ ) or $\left[{ }^{3} \mathrm{H}\right]$ EAPA (Fig. $1 \mathrm{~B}$ ) induced by propranolol in FMLP-stimulated PMN correlated with enhancement or suppression of NADPH oxidase activity studied in intact PMN (Fig. 6) or in subcellular fractions (Fig. 7). Second, the accumulation of 1,2DG (Fig. $2 \mathrm{~A}$ ) did not correlate with the activation of NADPH oxidase. Although this does not constitute adequate evidence for the lack of involvement of DG in $\mathrm{O}_{2}^{-}$release $(6-8,20-22)$, our results show that, at $500 \mu \mathrm{M}$ propranolol, there was no marked reduction in DG, although both $\mathrm{O}_{2}$ consumption (Fig. 6) and NADPH oxidase activity (Fig. 7) were strongly inhibited. The lack of formation of $\left[{ }^{3} \mathrm{H}\right] \mathrm{EAG}$ (Fig. $2 \mathrm{~B}$ ), despite observed increases in the mass of DG (Fig. 2A), suggests that phospholipids other than PC, possibly the phosphoinositides, contribute to the accumulation of 1,2-DG. This notion is supported by previous reports indicating that PA $(46,47)$, which accumulated in our studies, and propranolol (43) activate PLC to hydrolyze $\mathrm{PIP}_{2}$. Finally, exogenously added didecanoyl-PA activated NADPH oxidase in a reconstitution assay in the absence or presence of SDS (Table I). This result is supported by an earlier study (5) in which PA activated $\mathrm{O}_{2}^{-}$production in plasma membrane extracts of pig neutrophils in the absence of cytosolic factor.

Taken together, these data strongly implicate PA as a second messenger, and identify PC-hydrolyzing PLD as a significant pathway for NADPH oxidase activation in human PMN. It remains to be clarified whether diacyl-PA and/or alkylacylPA (Fig. 4) are functional in the activation of the oxidase. Further studies involving a characterization of the molecular species of endogenous PA generated by various agonists will prove helpful in determining the mechanism by which PA activates the oxidase in cell-free systems and in intact PMN. Such studies may also provide an explanation for the observed differences in the level of the oxidase measured in particulate fractions from intact cells pretreated with propranolol and stimulated with FMLP (Fig. 7, a fivefold increase at $300 \mu \mathrm{M}$ propranolol) compared with the ability of exogenous PA to activate NADPH oxidase in a cell-free system (Table I, a twofold increase using $300 \mu \mathrm{M}$ didecanoyl-PA). It is possible that the higher activity obtained in particulate fractions when intact cells are stimulated relates to the type of endogenous PA generated. Another possibility is that endogenously formed DG may be involved in modulating the activation of the oxidase by PA (3-6) as has been suggested (29-33).

We have not yet defined the mechanism by which PA activates NADPH oxidase, but there are several possibilities. PA, as an anionic amphipathic molecule, may directly interact with cytosolic and/or membrane components of the NADPH oxidase complex, perhaps enhancing its assembly through conformational changes in one or more of its elements. The possibility that this is a mechanism by which PA functions is supported by our observations that PA is a weak activator and that it amplifies the effect of SDS in activation of NADPH oxidase in a cell-free system. It is possible that high concentrations of propranolol inhibit activation of NADPH oxidase by either reducing the production of PA through the inhibition of PC-PLD or by binding PA and rendering it unavailable as a substrate in enzymatic reactions, as was suggested for the inhibition of PAP (30). Another mechanism by which PA may serve as a second messenger is through the activation of enzymes that lie proximal to the assembly of NADPH oxidase. One such enzyme 
may be PKC, since PA can serve as a cofactor in the activation of PKC in vitro (48) and PKC has been implicated in the activation of the oxidase $(6,49)$. More study is needed to determine whether PA and propranolol directly affect the assembly of the multicomponent NADPH oxidase, or indirectly regulate NADPH oxidase activation through PKC or other enzyme-dependent mechanisms.

Propranolol clearly can be used for studying the role of PA in cellular responses, but propranolol has pleiotropic effects on cells, and caution must be exercised in interpreting its effects. Propranolol is a cationic amphipathic molecule that blocks $\beta$ adrenergic receptors at concentrations that are $1 / 100$ th that needed for inducing its amphipathic effect (50-52). As a drug administered to humans, propranolol is provided as a racemic mixture of $D$ - and L-isomers (53). We have found that the racemic mixture used in these studies and the stereoisomers are equipotent in altering PMN responses and lipid metabolism (unpublished observations) and conclude that the effects of propranolol on PMN do not occur through blockage of the $\beta$-adrenergic receptor, but rather through its amphipathic properties. Propranolol concentrates on the inner leaflet of cells, the area of the bilayer structure where PC and phosphatidylserine predominate (54). The interaction of propranolol with one or both of these phospholipids in addition to concomitant changes in membrane fluidity are potential mechanisms by which the agent exerts its effects $(55,56)$.

In summary, we conclude that: (a) PA is a second messenger for activation of NADPH oxidase in human PMN; and $(b)$ propranolol, through its concentration-dependent effects on PA phosphohydrolase and PLD, causes a bimodal accumulation of PA and can be used to evaluate the role for PA in a number of cellular responses.

\section{Acknowledgments}

We thank Sue Cousart, Cathy Soldato-Couture, and Diane Qualliotine-Mann for technical assistance, Mary Green and Jennifer Peterson for secretarial help.

This work was supported by National Institute of Health grants NIAID AI-09169 (C. E. McCall), AI-22564 (L. C. McPhail), and AI14929 (D. A. Bass). S. Sozzani was supported by a fellowship from Mr. L. Berti, Champion Industries, Winston-Salem, NC.

\section{References}

1. Babior, B. M. 1984. Oxidants from phagocytes: Agents of defense and destruction. Blood. 64:959-966.

2. McPhail, L. C., and R. Snyderman. 1983. Activation of the respiratory burst enzyme in human polymorphonuclear leukocytes by chemoattractants and other soluble stimuli. J. Clin. Invest. 72:192-200.

3. Rossi, F., M. Grzeskowiak, V. Della-Bianca, F. Calzetti, and G. Gandini. 1990. Phosphatidic acid and not diacylglycerol generated by phospholipase $D$ is functionally linked to the activation of the NADPH oxidase by FMLP in human neutrophils. Biochem. Biophys. Res. Commun. 168:320-327.

4. Ohtsuka, T., M. Ozawa, N. Okamura, and S. Ishibashi. 1989. Stimulatory effects of short chain phosphatidate on superoxide anion production in guinea pig polymorphonuclear leukocytes. J. Biochem. 106:259-263.

5. Bellavite, P., F. Corso, S. Dusi, M. Grzeskowiak, V. Della-Bianca, and F. Rossi. 1988. Activation of NADPH-dependent superoxide production in plasma membrane extracts of pig neutrophils by phosphatidic acid. J. Biol. Chem. 263:8210-8214.

6. Cox, C. C., R. W. Dougherty, B. R. Ganong, R. M. Bell, J. E. Niedel, and R. Snyderman. 1986. Differential stimulation of the respiratory burst and lysosomal enzyme secretion in human polymorphonuclear leukocytes by synthetic diacylglycerols. J. Immunol. 136:4611-4616.

7. Rider, L. G., and J. E. Niedel. 1987. Diacylglycerol accumulation and superoxide anion production in stimulated human neutrophils. J. Biol. Chem. 262:5603-5608.

8. Bass, D. A., L. C. McPhail, J. D. Schmitt, S. Morris-Natschke, C. E. McCall, and R. L. Wykle. 1989. Selective priming of rate and duration of the respiratory burst of neutrophils by 1,2-diacyl- and 1-O-alkyl-2-acyl diglycerides. J. Biol. Chem. 263:19610-19617.

9. Smith, C. D., B. C. Lane, I. Kusaka, M. W. Verghese, and R. Snyderman. 1985. Chemoattractant receptor-induced hydrolysis of phosphatidylinositol 4,5bisphosphate in human polymorphonuclear leukocyte membrane. J. Biol. Chem. 260:5875-5878.

10. Takenawa, T., J. Ishitoya, Y. Homma, M. Kato, and Y. Nagai. 1985. Role of enhanced inositol phospholipid metabolism in neutrophil activation. Biochem. Pharmacol. 34:1931-1935.

11. Volpi, M., R. Yassin, P. H. Naccache, and R. I. Sha'afi. 1983. Chemotactic factor causes rapid decrease in phosphatidylinositol 4,5-bisphosphate and phosphatidylinositol 4-monophosphate in rabbit neutrophils. Biochem. Biophys. Res. Commun. 112:957-963.

12. Ishitoya, J., A. Yamakawa, and T. Takenawa. 1987. Translocation of diacylglycerol kinase in response to chemotactic peptide and phorbol ester in neutrophils. Biochem. Biophys. Res. Commun. 144:1025-1030.

13. Agwu, D. E., L. C. McPhail, R. L. Wykle, and C. E. McCall. 1989. Mass determination of receptor-mediated accumulation of phosphatidate and diglycerides in human neutrophils measured by Coomassie blue staining and densitometry. Biochem. Biophys. Res. Commun. 159:79-86.

14. Agwu, D. E., L. C. McPhail, M. C. Chabot, L. W. Daniel, R. L. Wykle, and C. E. McCall. 1989. Choline-linked phosphoglycerides. A source of phosphatidic acid and diglycerides in stimulated neutrophils. J. Biol. Chem. 264:1405-1413.

15. Pai, J-K., M. I. Siegel, R. W. Egan, and M. M. Billah. 1988. Phospholipase D catalyses phospholipid metabolism in chemotactic peptide-stimulated HL-60 granulocytes. J. Biol. Chem. 263:12472-12477.

16. Pai, J-K., M. I. Siegel, R. W. Egan, and M. M. Billah. 1988. Activation of phospholipase D by chemotactic peptide in HL-60 granulocytes. Biochem. Biophys. Res. Commun. 150:355-364.

17. Billah, M. M., S. Eckel, T. J. Mullman, R. W. Egan, and M. I. Siegel. 1989. Phosphatidylcholine hydrolysis by phospholipase D determines phosphatidate and diglyceride levels in chemotactic peptide-stimulated human neutrophils. $J$. Biol. Chem. 264:17069-17077.

18. Gelas, P., G. Ribbes, M. Record, F. Terce, and H. Chap. 1989. Differential activation by $\mathrm{fMet}-\mathrm{Leu}-\mathrm{Phe}$ and phorbol ester of a membrane phosphatidylcholine-specific phospholipase D in human neutrophils. FEBS (Fed. Eur. Biochem. Soc.) Lett. 251:213-218.

19. Martin, T. W. 1988. Formation of diacylglycerol by a phospholipase Dphosphatidate phosphatase pathway specific for phosphatidylcholine in endothelial cells. Biochem. Biophys. Acta. 962:282-296.

20. Smith, R. J., L. M. Sam, and J. M. Justen. 1988. Diacylglycerols modulate human polymorphonuclear neutrophil responsiveness: effects on intracellular calcium mobilizations, granule exocytosis, and superoxide anion production. $J$. Leukocyte Biol. 43:411-419.

21. Bass, D. A., C. Gerard, P. Olbrantz, J. Wilson, C. E. McCall, and L. C. McPhail. 1987. Priming of the respiratory burst of neutrophils by diacylglycerol. Independence from activation of translocation of protein kinase C. J. Biol. Chem. 262:6643-6649.

22. Bonser, R. W., N. T. Thompson, R. W. Randall, and L. G. Garland. 1989. Phospholipase $\mathrm{D}$ activation is functionally linked to superoxide generation in the human neutrophil. Biochem. J. 264:617-620.

23. Koenderman, L., A. Tool, D. Roos, and A. J. Verhoeven. 1989. 1,2-Diacylglycerol accumulation in human neutrophils does not correlate with respiratory burst accumulation. FEBS (Fed. Eur. Biochem. Soc.) Lett. 243:399-403.

24. Della Bianca, V., M. Grzeskowiak, M. A. Cassatella, L. Zeni, and F. Rossi. 1986. Phorbol 12, myristate 13 , acetate potentiates the respiratory burst while inhibits phosphoinositide hydrolysis and calcium mobilization by formyl-methionyl-leucyl-phenylalanine in neutrophils. Biochem. Biophys. Res. Commun. 135:556-565.

25. Grzeskowiak, M., V. Della Bianca, M. A. Cassatella, and F. Rossi. 1986. Complete dissociation between activation of phosphoinositide turnover and of NADPH oxidase by formyl-methionyl-leucyl-phenylalanine in human neutrophils depleted of $\mathrm{Ca}^{2+}$ and primed by subthreshold doses of phorbol 12, myristate 13, acetate. Biochem. Biophys. Res. Commun. 135:785-794.

26. Rossi, F., M. Grzeskowiak, and V. Della Bianca. 1986. Double stimulation with FMLP and Con A restores the activation of the respiratory burst but not of the phosphoinositide turnover in $\mathrm{Ca}^{2+}$-depleted human neutrophils. A further example of dissociation between stimulation of the NADPH oxidase and phosphoinositide turnover. Biochem. Biophys. Res. Commun. 140:1-11.

27. Tyagi, R. J., M. Tamura, D. N. Burnham, and J. D. Lambeth. 1988. Phorbol myristate acetate (PMA) auguments chemoattractant-induced diglyceride generation in human neutrophils but inhibits phosphoinositide hydrolysis. $J$. Biol. Chem. 263:13191-13198.

28. Burnham, D. N., D. J. Uhlinger, and J. D. Lambeth. 1990. Diradylglycerol synergizes with an anionic amphiphile to activate superoxide generation and phosphorylation of $\mathrm{p} 47_{\text {phox }}$ in a cell-free system from human neutrophils. $J$. Biol. Chem. 265:17550-17559.

29. Korchak, H. M., L. B. Vosshal, K. A. Haines, C. Wilkenfeld, K. F. Lundquist, and G. Weissmann. 1988. Activation of human neutrophils by calciummobilizing ligands. II. Correlation of calcium, diacylglycerol and phosphatidic 
acid generation with superoxide anion generation. J. Biol. Chem. 263:1109811105 .

30. Pappu, A. S., and G. Hauser. 1983. Propranolol-induced inhibition of rat brain cytoplasmic phosphatidate phosphohydrolase. Neurochem. Res. 8:15651575.

31. Koul, O., and G. Hauser. 1987. Modulation of rat brain cytosolic phosphatidate phosphohydrolase: Effect of cationic amphophilic drugs and divalent cations. Arch. Biochem. Biophys. 253:453-461.

32. Bauldry, S. A., D. A. Bass, S. L. Cousart, and C. E. McCall. 1991. Tumor necrosis factor $\alpha$ priming of phospholipase $\mathrm{D}$ in human neutrophils. Correlation between phosphatidic acid production and superoxide generation. J. Biol. Chem. 266:4173-4179.

33. English, D., and G. S. Taylor. 1991. Divergent effects of propranolol on neutrophil superoxide release: Involvement of phosphatidic acid and diacylglycerol as second messengers. Biochem. Biophys. Res. Commun. 175:423-429.

34. Surles, J. R., R. L. Wykle, J. T. O'Flaherty, W. L. Salzer, M. J. Thomas, F Snyder, and C. Piantadosi. 1985. Facile synthesis of platelet-activating factor and racemic analogues containing unsaturation in the $s n-1$-alkyl chain. $J$. Med. Chem. 28:73-78.

35. Chilton, F. H., J. M. Ellis, S. C. Olson, and R. L. Wykle. 1984. 1-O-Alkyl2-arachidonoyl-sn-glycero-3-phosphocholine. A common source of platelet-activating factor and arachidonate in human polymorphonuclear leukocytes. J. Biol. Chem. 259:12014-12019.

36. Bligh, E. G., and W. J. Dyer. 1959. A rapid method of total lipid extraction and purification. Can. J. Biochem. Physiol. 37:911-917.

37. Tamer, A. E., M. Record, J. Fauvel, H. Chap, and L. Douste-Blazy. 1984. Studies on ether phospholipids. I. A new method of determination using phospholipase $A_{1}$ from guinea pig pancreas: Application to Krebs II ascites cells. Biochem. Biophys. Acta. 793:213-220.

38. Parks, J. S., B. C. Bullock, and L. C. Rudel. 1989. The reactivity of plasma phospholipids with lecithin: cholesterol acyltransferase is decreased in fish-oil fed monkeys. J. Biol. Chem. 264:2545-2551.

39. Caldwell, S. E., C. E. McCall, C. L. Hendricks, P. A. Leone, D. A. Bass, and L. C. McPhail. 1988. Coregulation of NADPH oxidase activation and phosphorylation of a 48-KD protein(s) by a cytosolic factor defective in autosomal recessive chronic granulomatous disease. $J$. Clin. Invest. 81:1485-1496.

40. Smith, P. K., R. I. Krohn, G. T. Hermanson, A. K. Mallia, F. H. Gartner, M. D. Provenzano, E. K. Fujimoto, N. M. Goeke, B. J. Olson, and D. C. Klenk. 1985. Measurement of protein using bicinchoninic acid. Anal. Biochem. 150:7685 .

41. Massey, V. 1959. The microestimation of succinate and the extinction coefficient of cytochrome C. Biochim. Biophys. Acta. 34:255-256.

42. McPhail, L. C., P. S. Shirley, C. C. Clayton, and R. Snyderman. 1985. Activation of the respiratory burst enzyme from human neutrophils in a cell-free system. Evidence for a soluble factor. J. Clin. Invest. 75:1735-1739.
43. Das, J., J. DeBelleroche, and S. Hirch. 1988. Stimulation of inositol phos phate production by propranolol in human neutrophils. Prog. Neuro-Psychopharmacol. \& Biol. Psychiatry. 12:721-726.

44. Truett, A. P., III, M. W. Verghese, S. B. Dillon, and R. Snyderman. 1988 Calcium influx stimulates a second pathway for sustained diacylglycerol production in leukocytes activated by chemoattractants. Proc. Natl. Acad. Sci. USA. 85:1549-1553.

45. Reibman, J., H. M. Korchak, L. B. Vosshall, K. A. Haines, A. B. Rich, and G. Weissmann. 1988. Changes in diacylglycerol labeling, cell shape, and protein phosphorylation distinguish "triggering" from "activation" of human neutrophils. J. Biol. Chem. 263:6322-6328.

46. Kroll, M. H., G. B. Zavoico, and A. I. Schafer. 1989. Second messenge function of phosphatidic acid in platelet activation. J. Cell. Physiol. 139:558-564.

47. Jackowski, S., and C. O. Rock. 1989. Stimulation of phosphatidylinositol 4,5-bisphosphate phospholipase C activity by phosphatidic acid. Arch. Biochem. Biophys. 268:516-524.

48. Takai, Y., A. Kishimoto, U. Kikkawa, T. Mori, and Y. Nishizuka. 1979. Unsaturated diacylglycerol as a possible messenger for the activation of calciumactivated, phospholipid-dependent protein kinase system. Biochem. Biophys. Res. Commun. 91:1218-1224.

49. Gerard, C., L. C. McPhail, A. Marfat, N. P. Stimler-Gerard, D. A. Bass, and C. E. McCall. 1986. Role of protein kinases in stimulation of human polymorphonuclear leukocyte oxidative metabolism by various agonists: differential effects of a novel protein kinase inhibitor. J. Clin. Invest. 77:61-65.

50. Murray, K. T., C. Reilly, R. P. Koshakji, D. M. Roden, M. D. Lineberry, A. J. J. Wood, L. A. Siddoway, J. T. Barbey, and R. L. Woosley. 1990. Suppression of ventricular arrhythmias in man by d-propranolol independent of $\beta$-adrenergic receptor blockade. J. Clin. Invest. 85:836-842.

51. Barrett, A. M., and V. A. Cullum. 1968. The biological properties of the optical isomers of propranolol and their effects on cardiac arrhythmias. Br. J. Pharmacol. 34:43-55.

52. Farmer, J. B., and G. P. Levy. 1968. A comparison of some cardiovascular properties of propranolol, MJ1999 and quinidine in relation to their effects in hypertensive animals. Br. J. Pharmacol. 34:116-126.

53. Howe, R., and R. G. Shanks. 1966. Optical isomers of propranolol. Nature (Lond) 210:1336-1338.

54. Dachary-Prigent, J., J. Dufourcq, C. Lussan, and M. Boissea. 1979. Propranolol, chlorpromazine, and platelet membrane: a fluorescence study of the drug-membrane interaction. Thromb. Res. 14:15-22.

55. Kerry, P., M. C. Scrutton, and R. B. Wallis. 1984. $\beta$-Adrenoceptor antagonists and human platelets: relationship of effects to lipid solubility. Biochem. Pharmacol. 33:2615-2622.

56. Dash, D., and G. R. K. Rao. 1990. Characterization of the effects of propranolol on the physical state of the membrane. Arch. Biochem. Biophys. 276:343-347. 